\title{
Celebrity Auto/Biography and the Construction of Ageing Selves
}

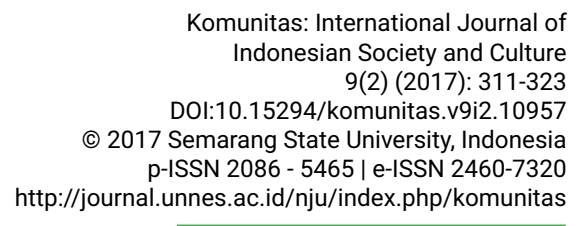

UNNDS

JOURNALS

\section{Aquarini Priyatna ${ }^{1}$}

${ }^{1}$ Department of Literature and Cultural Studies, Universitas Padjadjaran, Indonesia

Received: March 2016; Accepted: August 2016; Published: September 2017

\begin{abstract}
This paper investigates the notion ageing femininity as it is performed within the frame of celebrity culture which privileges youthfulness in beauty and body image. It focuses on the issues of age, the process of ageing, the significance of ageing, the impact of ageing as part of the construction of celebrity identity and femininity. Age[ing] is an important context that female celebrities need to negotiate and embrace the ways in which cultural values need to be considered as well. Looking into the portrayal of the auto/biographical subjects and the visual images used, the paper argues that celebrities negotiate, transform and extend their forms of femininity as they age. Both auto/biographies present their auto/biographical subjects to show the construction of appealing ageing celebrity femininities that are closely linked to the characteristics of the Third Agers, being fit, fashionable, functional and flexible.
\end{abstract}

\section{Keywords}

ageing femininity; celebrity; beauty; body image; auto/biography

\section{INTRODUCTION}

In this article, I am looking at the auto/biographies of two Indonesian female celebrities, namely Titik Puspa and Lenny Marline. Their auto/biographies, respectively entitled Titiek Puspa: A Legendary Diva, written by Alberthiene Endah and Si Lenny dari Ciateul: Otobiografi Lenny Marlina, written by a team of five writers, namely Titie Said, Lies Said, Muthiah Alhasany, Titien Sukmono, and Yuni.

The term "celebrities" here refers to glamour celebrities, namely those who work in the entertainment industry or show business, and who encompass various types of entertainment profession (D. P. Marshall, 2001). The term "auto/biography" is used because it is a critical intersection of the overlapping practices of autobiography and biography. This paper is informed by the critical approaches both to biographies and autobiographies and argues that the term "auto/biography" is appropriately applied to the new forms of autobiographical practice being generated in Indonesian mass culture by specifically female celebrities.

Initially Lejeunne (1989, p.xvi) offered the conventional definition of autobiography as "retrospective prose narrative that someone writes concerning his [sic] own

\footnotetext{
Corresponding author

Faculty of Cultural Sciences, Jl. Raya Jatinangor Km

21, Jatinangor Sumedang

Email

aquarini@unpad.ac.id
} 
existence". In his later works, this definition has been expanded to include the different ways of "referential self-expression...in contemporary culture", as Eakin (1989, p.xvii) proposes:

\begin{abstract}
"Someone" might well include someone else, a ghostwriter, say, or oral historian, while the "prose narrative" in question might in fact be a transcript or oral discourse, broadcast on the radio or presented in film. The ownership implicit in the phrase "his own life," moreover, was now frequently a subject of litigation.
\end{abstract}

In this way, autobiography, which generically means "self-life-writing" (Stanley, 1992, p.43), can potentially include biography as in "life-writing" written by others. As Lejeune has outlined, the boundary of autobiography and biography is becoming blurred. The same argument is raised by Bakhtin (1981, p.132) who asserts that "there could not in principle be any difference between the approach one took to another's life and to one's own, that is, between the biographical and the autobiographical point of view." Following Bakhtin, Marcus (1994, p.15) argues that "autobiography" is a "hybrid form" where the "perceived instability and hybridity... are inextricably linked to the problematics of selfhood and identity, with the boundaries between 'inner' and 'outer', 'private' and 'public' becoming the sites of the greatest concern." Thus, her use of the term "auto/biographical" suggests this collapse between autobiography and biography as well as the blurring of various domains that establish auto/biographical subjects.

The discussion on auto/biography by/on women also raises the issues of the content included in the auto/biography. With the conventional auto/biography telling the narrative of success of male auto/ biographer where public achievement is the primary focus, the auto/biography by/on women tells more of personal, the everyday, and even those considered trivial. As Miller (2002) observes, there is often an exclusion of the everyday as minor and insignificant in traditional auto/biographies. However, "trivial writings" such as female celebrity auto/biography act as a valuable form of history, in which particular and specific details of the experience of self at a specific locality of time and space constitute a valuable picture of the self. In producing their lived experiences in these formats, women reveal not only their own identities and subjectivities, but also the history, politics and social landscape of their daily lives. By taking up these "trivial" issues, women "talk back" to the structures that mute them.

Through auto/biographies, women establish a space wherein their subjectivities are established by making their lives matter, their opinions surface and their perspectives heard. Cosslett et al maintain "[i]f women have been categorized as "objects" by patriarchal cultures, women's autobiography gives an opportunity for them to express themselves as "subjects", with their own selfhood" (Cosslett, Lury, \& Summerfield 2000, p.6). Being women and celebrities and ageing, the celebrities discussed in this research touch the different significant issues in what it means to be ageing in contemporary popular culture in Indonesia. I am arguing that auto/biographies of Indonesian female celebrities offer opportunities to negotiate women's positioning in the cultures that objectify them by subverting existing conventional frameworks (Ussher 1997). More specifically by the blurring of private and public implied in the use of the term auto/ biography.

The term "autobiography" suggests the clear difference between "self and world, literature and history, fact and fiction, subject and object" (Marcus 1994, p.7) and it assumes the containment and the distinctiveness of the subject. Such attributes also imply the knowability of the autobiographical subject, which this article argues otherwise. I am thus proposing that the term "auto/biography" provides more space for potential blurring of such containment. I argue that femininities, particularly as performed by female celebrities are fragmented yet coherent and drawing on complex ideas of public and private.

Following the frameworks of, among 
others, Marshall (2001), Littler (2004), Gamson (1994), Turner (2004) and Dugdale's (1999) analysis of celebrity and celebrity culture, I study celebrity auto/biography using an interdisciplinary approach grounded in feminist theories, cultural studies and literary criticism. Thus, I read and interpret the auto/biographies both as signs and also as social, cultural, and economic occurrences. I argue that in thinking of the phenomenon of celebrities, various frameworks must be taken into account because the phenomenon itself not only situates the representations but also engages complex issues of consumption, audience and reception.

Using the concept of "ageing successfully" combined with the previous understanding proposed by Marshall and Rahman (2015) on the construction of the Third Age, the article examines how the two auto/ biographical subjects are portrayed to have fulfilled the requirement of being in the category of the Third Age, ticking every single F required: fit, fashionable, functional and flexible. More specifically, the article takes a close look at how the two auto/biographies deal with the issue of beauty and body that benefit the young un-ageing face and the slim body. In this part of the article examines how the two celebrities navigate around the challenges to portray their [un]ageing bodies in cultures that highly value youthfulness and at the same time to highlight their maturity and well-established celebrity status that actually recognize their seniority.

\section{AGEING AND CELEBRITY CUL- TURE}

This subsection examines in more depth how ageing femininity is depicted both through the textual as well as the photographic narratives. The two auto/biographies discussed are quite similarly structured, written by other writers but using the first-person narrative, "I", as if it was written by the celebrities themselves, and not by other writers. Both auto/biographies are written in chronological order and both have the conventional auto/biographical plot of bildungsroman, where the celebrities are depicted as survivors and victors. Both Lenny Marlina and Titiek Puspa are described to have been able to overcome the various obstacles and hardship, financial and otherwise, in their respective life and emerged as prominent, contented, and wealthy celebrities. These auto/ biographies are important to look at for this research because not only they were published to mark the crucial stepping stone in terms of the age fifty and seventy but also as Marshall argues celebrity is "the embodiment of the battleground" of our own social cultural values and structure (2001, p.65). Research on how these celebrities portray their experience of ageing can arguably provide some understanding about how ageing is perceived within the context of Indonesian locality and Indonesian popular culture in general.

\section{BODY IMAGE AND THE CON- STRUCTION OF YOUTHFUL SELF}

Comparing the two auto/biographies at hand, and thinking of body and beauty as the primary markers of femininity, my attention is drawn to the auto/biography of Titiek Puspa. The title of the auto/biography suggests somewhat positively the issue of age as it claims Titiek Puspa to be "legendary". One can only be legendary when one has acquired enough age to be a legend. In the cover of the auto/biography, Titiek Puspa is portrayed to be wearing a highly decorated kebaya, Indonesian traditional costume. Her hair is also done in a traditional way, with hair bun and flowers. Her eyes are directed sideways, exposing her smooth face and neck. She looks so much younger than her seventy years old of age.

Titiek Puspa's auto/biography is very much structured like a fashion magazine, with images of her in glamorous gowns and background scattered predominantly throughout the book. Fashion, after all, "has always played a central part in the enactment of identity, mediating between the body and its scial presentation" (Twigg 2017, p.2). The first chapter of the book is illustrated by a two-page continuous image, 
half of which portrays Titiek Puspa in a golden highly glamorous long gown. Her hair is done up, her makeup is perfect. Again, her eyes are diverted sideways, her face and neck are exposed, free from wrinkles. Even through the first two images, it can be suggested that the narrative structure that lies heavily on the photographic narrative provides a way of blurring the age. The images unmistakably portray Titiek Puspa as a much younger person than she actually was at the time of the publication of the book. This portrayal already suggests the high investment of celebrity representation in fashion, particularly when age is present as a challenge to the normative youthful beauty. Furthermore, it also confirms that dress has always been "a significant part of selffashioning, and for many women is a source of pleasure, anxiety, interest, and concern" (Twigg, 2017, p.2), which will be elaborated later in this article.

On the first page of this chapter, a glamorous image of Titiek Puspa is presented. This glamour image is followed in the adjacent page by the title of the chapter which refers to her experience of economic disadvantage; the time when she was so poor, she even ate cat's food (the head of the salted fish, which is not usually consumed by people). This contrast blurs the temporal relationship between the image and the narrative. While the narrative reveals the auto/biographical subject in the position of a poor girl, the image shows the auto/biographical subject in her position as a Diva, a beautiful, successful, and wealthy woman. Deeper reading into the narrative also finds discrepancy with the image as the narrative tells in detail the skin diseases that contributes to her being unappealing as a child, while the image shows no traces of the skin diseases, erasing the younger poor self and replaces it with the older and wealthier Self -who nevertheless still retains her youthfulness and beauty. As Jerslev contends, "[i] mages of ageing celebrities inevitably refers back to photographs of their younger selves" (2017 p.11).

It can be argued that the juxtaposition of the images suggests agelessness. Age is made absent through the depiction of transcendence of chronological age and disconnection from the actual narrative following the image. Keeping in mind the framework of successful ageing, Titiek Puspa is shown to have been able to "cheat" age. Her portrayal of self is represented by a young[er] version of herself, who is both herself and not. Following Richards, Jerslev (2017, p.11) points out that fashion photography, which is shown in Titiek Puspa's auto/biography, "may free their appearance from the sentimentality and air of times-gone-by that can be associated with staged photographs of elderly women".

However, despite, or because of, the very fashionable gowns, some of the photographs reveal the tension between the desire to portray youthfulness and the reality of old age because the chronological facial features and bodies cannot always be transcended. The image of Titiek Puspa in Cleopatra-like gown and hairstyle presents an ambiguous auto/biographical subject, who is neither old nor young and who is simultaneously both old and young. She is both herself and other.

In this image Titiek Puspa's attempt to manage her seventy year-old identity has been complicated by the fact that age is negatively contextualized. This ordinary image of her "looking young" in her seventies can cross over into "unusual", namely "strange" and "unnatural", which may explain why this image is not very successful in its attempt to portray her age-defying image. As Biggs (2004) argues, the equation of youth to beauty is problematic for mature women. A seventy-year-old woman who attempts to look thirty or even twenty is disconcerting. It is even more disturbing when an older woman is portrayed to be sexual. While "wellpreserved" (Bildtgård, 200o) older women are more easily 'allowed' to create a sexual image of herself, in general women's older bodies and sexuality are considered revolting (Vares 2009).

The consciousness of concealing age implies the consciousness of its presence. The marks of the age itself remain adamant. Early in her auto/biography, Titiek Puspa 
has already addressed the issue of ageing as she shares the story of finding "wrinkles [...] playing more cheerfully" (Endah 2008, p.13) in her face, then tells, "luckily I like making up, wearing powder and blush on, so that I can still play hide and seek with wrinkles" (Endah 2008, p.13). Here age is presented as a game over which she has power to choose either to submit to it or to resist it, and makeup is a technology used to negotiate the ageing skin. However, it can also be argued that wrinkles as the representation of age is presented as something embarrassing, if not shameful, that needs to be hidden, and make up is a form of body management applied specifically to manage age.

Other body management is observed in her daily life, portrayed in the advertisements she models. In the latter part of the book, there are pages of commercial narratives where she is the model of. In those pages she describes the various "recipes" to her young-looking body and face. The first advertisement to appear is a milk brand targeting for adult people. In the copy of the advertisement, Titiek Puspa explains at length how she maintains a healthy lifestyle to keep fit and active, illustrated by various images of her drinking the milk, showing how healthy and fit she is. All images show her at work, again illustrating her functionality and flexibility, "... my body is still dynamic in carrying out my different activities" (Endah 2008, p.335).

The following advertisement is for "natural cosmetics" boasting to have been derived from Indonesian traditional recipe of beauty. Titiek Puspa's motto as she conveys is actually used as the tagline of the advertisement, "The Secret to keep youthful and free from stress". Her youthful body image and beauty show how "well-preserved" she is and they have become her investment not only for living a functional life, but also to continue working as a professional performer.

As I have outlined, maintaining a particular bodily appearance is crucial in normative forms of femininity. While the arrangement of the images obscures a coherent, chronological narrative, it functions as a strategy for "age management" (Biggs 2004), through which one defies one's age and conceals it through narrative.

In Titiek Puspa's auto/biography, the present is stabilized in the glossy colored images taken in studios or other "sterilized" spaces, while the past is mostly suggested through black and white images. I offer further examples of how Titiek Puspa's age is managed through the deployment of sporadic images of herself in the present time and in the past, i.e. pictures of herself as a seventy year- old woman and the counterposing images of herself at younger ages.

Five pages into Chapter One of Titiek Puspa's auto/biography, the readers are exposed to an old family picture in black and white dated 1948, taken during the difficult period of war and food scarcity. This image would actually best illustrate the title as the chapter generally describes their difficult life as a big family with so many mouths to feed. The image thus denotes a distant difficult past when Titiek Puspa was young and poor.

However, just like the illustration of the opening of Chapter One where the "sad title" is illustrated by a glamorous image of a diva, the picture that refers to their hard past is also countered by another image of the glorious present. I argue that this narrative strategy can also be argued to be a form of age management in the representation of female celebrities. While the "poor" image represents her youth, the current glamorous diva image attempts to retain and renegotiate her youthful image through the instruments of adornments, gown, make-up and hairstyle. Her age is camouflaged, yet her status is highlighted. Similar images are presented throughout the book. The figure placed four pages later portrays Titiek Puspa looking soulfully outside and literally under the light, wearing yet another gown with the color of gold, the symbol of wealth and success. The image reiterates how age is denied through dress and adornments functioning to imply her agelessness. The overly glamorized gowns that she wears in the images are not relevant to any specific time frame of her life. In other words, her gowns do not mark the time in which the auto/biographical 
subject is located.

The unchronological arrangement of the time frames of the narrative and the images throughout the book obscures the age of the auto/biographical subject throughout the book. As we read the text and flip the images, we lose a sense of the subject's chronology and it exposes the readers to gaps and ruptures in the performance of the autobiographical subjects. The auto/ biographical subject produced in this kind of photographic narrative is inevitably fragmented. The irony, as Dyer (1987) argues, is that while we are aware that this celebrity is fragmented both by time and by its split into ordinary and extraordinary iterations, we are encouraged to see that there is consistency and coherence among the different images and in this way we are led to believe that she is one and the "same". This then highlights that ageing femininity in female ageing celebrity auto/biographies renders age as absence. The age, especially in the case of Titiek Puspa, is so publicized and familiar that it is not significant anymore. The readers of the auto/biography are led to the idea that no matter what age she is, she remains the same Titiek Puspa as she was when she began her humble beginning in a small town in Central Java.

One image, only three pages from the last three images discussed above, is a zoom-in photograph that brings the readers closer to Titiek Puspa's face. It invites the audience to see her not-so-wrinkled face as well as her quite-wrinkled hands. This "natural" image again obscures the time. Her simple outfit, the modest make up and the very simple hair cut imply a more approachable and ordinary persona. Despite, or because of, some inconsistency, this image represents her as an everyday person. Without the masquerade of gowns and excessive adornment, her age is absent. Her short hair suggests youth but the wrinkled hands suggest otherwise. Her minimal adornment - very simple earrings, glasses, and a ring paradoxically invoke youth and simplicity. I argue that this image presents "ageing successfully" in which age is not totally denied but her "well-preserved" face is emphasized.

This image is later juxtaposed with images of her when she was really young in other images. Despite the age difference, the two images establish the coherence and validity of her "natural" appearance at seventy in the other image. This juxtaposition suggests nothing has changed. She is as youthful in her seventies as she was in her twenties or thirties.

Apart from looking young, in her auto/biography Titiek Puspa is also described to be what is identified as Third Age, namely older people who are fit, fashionable, functional, flexible. I have discussed how she is portrayed to be still beautiful and in some regards young in a rather complex way. Throughout the book, seventy-year-old Titiek Puspa is pictured to have continued being productive as a song writer, and active as a singer. While rumors that she had a plastic surgery to maintain her very younglooking face still circulates (Lesmana, 2013), Titiek Puspa actually acknowledges her age, and considers the fact that she is still fit, functional and flexible - not to mention fashionable - as a blessing from God.

\begin{abstract}
"I am a granny now. I have reached the age of 7os. People say it's the time to retire, to rest. The fact that I can still be performing on stage, singing, and a little bit dancing, it's a blessing from God" (Endah 2008, p.257)
\end{abstract}

Apart from the highly choreographed pictures of her in haute couture gowns, the auto/biography also includes quite extensively - twenty three pages altogether - of various candid pictures of her during the concert to celebrate her $70^{\text {th }}$ birthday. The pictures portray her laughing, singing, dancing, rehearsing, and playing around. Professionally she is a very much functioning performer. Her schedule is still tight, and she still earns money that contributes to her agency and independence, "One thing that I am really grateful is that in my seventy years of age, I still can earn my own living..." (Endah 2008, p.9). More than that, she finds work rewarding and fulfilling. 


\begin{abstract}
"My secretary told me that I had calls requesting for cooperation. My designer told me that my dream gown has been ready and it's beautiful. My grandchild called me and asked to meet. She wanted to talk about her boyfriend. Inul called me and said she missed me. The President invited me to sing in the Palace. Not to mention the never-ending invitations to sing abroad. What will you call that if not a blessing? I have a beautiful life" (Endah 2008, p.13).
\end{abstract}

What is important to note from her remark is that her sense of fulfilled self, with the recognition of her age, is built on different attributes, the profession, the financial power, the recognition, and the personal relationships with people around her: her family and friends. These are the issues dwelled in depth in her auto/biography, using her own perspective as she narrates to her auto/biographer. Alberthienne Endah, the writer of her auto/biography, aptly notes in her preface that the book is "a note from the heart of a woman" (Endah 2008, p.9). Titiek Puspa's auto/biography is about her personal life - her sense of being a woman, as much as it is about her professional life. The fact that her account of personal life constantly gives context to her account of her professional life means her experience of ageing is perceived positively, and instead of fearing the loss of her young face and body, she embraces it.

In the commercial for the milk product, she even compares her active life to those of women so much younger than herself, "I am grateful that in my 7os, I can still do the activities usually carried out by active young women" (Endah 2008, p.332). She further remarks that she still has so much enthusiasm for keeping her beauty through healthy lifestyle. This statement underlines again the work done to maintain youthful beauty, which she religiously observes.

In addition to maintaining active life, which is also her objective, she reiterates the healthy life that contributes to her youthful beauty. The title of the commercial of an
Indonesian "natural traditional cosmetics" that she models bluntly affirms "Natural Beauty, the secret to my youthfulness". This statement can be read firstly, as a form of knowledge sharing among women, taking beauty as a key issue in a woman's life. Secondly, Titiek Puspa acknowledges that people attribute to her as youthful. Thirdly, the advertisement both acknowledges people's opinion and also Titiek Puspa's recognition of her youthful beauty. The advertisement commodifies all those to its own benefit as evident in the tagline of the advertisement, "The secret for keeping youthful and free from stress" (Endah, 2008, p.340).

However, more than being the model of the product, Titiek Puspa also elaborates her relationship with Martha Tilaar, the owner of the company, that can be traced back to twenty-five years before when she modeled in the newly launched anti-ageing products of the company in 1983 when she was only 45 years old.

"My friendship with Martha Tilaar is still going strong till today. Now we're both women of 7 os. However, in our age that people think we should be "resting", we are still doing our girly chats, we are active doing this and that, and of course we still put on our makeup and be beautiful. We are happy that we have lived our seven decades of life upholding our womanly values" (Endah 2008, p.339).

Her depiction again shows her embracing the old age and specifically contributing her happy ageing experience as a woman in the context of her ability to maintain an active and happy lifestyle. This is further validated by her other cosmetics advertisement that she started to model when she was 60 years old. While there is no reference to her old age in the advertisement per se, the commercial narrative clearly makes age a point of significance as the cosmetics to claim it is good for the seventies as it is for the twenties, "cosmetics that is good for the twenty to forty year-old women might not be good for women in their seventies like me". The commercial narrative here can 
be argued to classify women based on age, but as the text goes, it is in fact constructing women to be ageless. It disregards women's actual needs and condition due to the difference of age and claims the "brand to pay attention to the needs of women of all ages" (Endah 2008, p.346). This claim is further elaborated by Titiek Puspa by saying how the cosmetics make her "feel as beautiful as a princess". Here Titiek Puspa's girlie excitement can be signified to radiate a form of desirable youthfulness. The reference to princesses is arguably a mainstream form of girlie desire and fantasy, which she manifests in the form of putting on makeup as girls make believe in playing adult women. Here, interestingly ageing is experienced as a chance to play a young woman, emphasizing again the construction of youthfulness as a desirable trait and quality.

The products that she represents in various advertisements included in the auto/ biography are part and parcel of the auto/ biography and I argue that her femininity is represented in the narrative and the images of the auto/biography as well as through the advertisements she models. Her youthfulness that is constantly featured in the advertisements that she models can be signified as a form of acknowledgment of her achievement in her body/age management. Considering the framework of "Third Age" as a perspective to see her portrayal, it can be argued that in her auto/biography, Titiek Puspa is depicted to belong to the category of the Third Age as a fit, fashionable, functional and flexible person. Her beauty and body are described to be "well-preserved" with various age management. In the portrayal in the auto/biography, while age is embraced and acknowledge, it is perceived as a manageable challenge that can be negotiated in many different ways. Following Entwistle (2000), age can be managed through the "technology of the Self" the ways in which one can somehow produce identity to meet certain purposes and/or to submit to certain norms.

\section{AGEING FEMININITY: TRANS- FORMATIONS AND ESTABLISH- MENT}

Unlike Titiek Puspa, who retains her glamorous femininity across her full life span, as very much reflected in her auto/biography, Lenny Marlina withdrew from the entertainment business when she married her second husband, who was a politician a month before she turned forty-five. This retirement from the show business did not end her celebrity status as she continues to appear in public as the wife of her politician husband. Much of her auto/biography is about her life and her relations with people close to her. She dwells on the issue of body and beauty in a different way from Titiek Puspa's, which I will argue to be a different way of portraying youthfulness and the Third Agers' attributes.

Lenny Marlina's auto/biography opens with a series of images of herself in the opening chapter entitled "Series of Self" - or perhaps more accurately "Series of Selves", ranging from the time she was in junior high school to the time when she's already married for the second time. Most of the images are candid pictures, which do reflect her age more accurately.

Mostly throughout the book Lenny Marlina is portrayed as a fresh healthy looking fifty-year-old woman. She does not wear heavy make-up or any glamorous clothing. The only image that can arguably be considered as fashion photography is the one on the cover of the auto/biography which draws on and reflects her images as it appeared in various magazines in her younger days (Said et al. 2004, p.xxiv-xxv). The similarities between this image on the cover of the auto/biography, the covers of various women's magazines and the advertisements included in the text indicate the deliberate effort to connect this auto/biography to women's magazines.

The inclusion of magazine covers throughout further strengthens this link and it makes an interesting visual narrative too. All the magazine covers included are dated 1982, when she was twenty-eight yea- 
rs old. What is interesting is that although the peak period of her career lasted quite a long time, the covers chosen for inclusion are from six different magazines all from the same year. I would argue that age twentyeight is located as the highpoint not only in terms of Lenny Marlina's career but also in her physical beauty. These images serve to solidify the beauty of Lenny Marlina the auto/biographical subject at one particular time, despite the auto/biography's account of transition and triumph.

I argue too that the portrayal of the auto/biographical subject in Lenny Marlina's auto/biography shows Lenny Marlina to be presenting as a number of different women in the year that she was twenty-eight: she is a calm and makeup-free woman as presented in Kartini; a heavily made up and adorned woman who presents a traditional concept of beauty in Sarinah; a sophisticated upperclass woman in Famili; a seductive persona in the clearly codified celebrity/global culture in Vista and Variasi, which are entertainment magazines; and a more "natural" woman in need of making up in Rias ("rias" in English means to put make up on), as dictated by the magazine. The constant visual reference to the age of twenty-eight suggests that she presents herself as both aged and timeless. By drawing on diverse images from one time of her life, these pictures of Lenny are simultaneously marking timelessness and an always existing present.

This transformation is articulated in her auto/biography through the particular portrayal of her femininity, which differs from the celebrity femininity that is imaged earlier in the text. Starting from the chapter "Getting Married Again", she no longer portrays herself as a glamorous celebrity. Rather, she retreats to a more conventional performance of femininity as a full-time housewife and partner. This transformation from celebrity femininity to her newly-embraced mode of traditional femininity is shown as simultaneously mature and youthful. At the same time, the second marriage affirms Lenny Marlina continued desirability as a woman despite her age. This confirms what Marshall argues, following Ingraham, that successful ageing is "dominated by a heterosexual imaginary, shaped by imagery which is "culturally persuasive, symbolically prolific, and rarely questioned or examined"” (2017, p.14).

Ingraham coins "heterosexual imaginary" to argue how heterosexuality is considered to be "sacred" and is natural[ized] the ways in which it is deemed necessary for well-being and happiness (2008). Using the framework of heterosexual imaginary, Marshall argues how successful ageing is equated to heterohappiness as portrayed by Leny Marlina's marriage to her second husband, who has somehow fulfilled the different aspirations considered to have not been fully manifested in her previous relationship with her first husband. As she narrates (Said et al., 2004), she longs to be able to depend on her husband but at the same time still has the space to be independent, to be a wife and at the same time to play her own public roles as as actress and a model.

As an illustration, the fact that Lenny Marlina has become a full-time wife does not necessarily require her complete withdrawal to the domestic domain, because ironically her new status as the wife of a prominent politician transforms her again into another type of celebrity, a public figure albeit in a different context. Her celebrity status metamorphosed and she is "rebranded" from a film star to a politically involved wife. Her already established fame as a film star is useful to her husband's effort to gain popularity in his political standing. She not only functions as a wife, but brings her celebrity status into her new femininity. Her continuous public appearances and meetings with important, such as the former presidents as well as other high-ranking officials and other prominent figures, sustain her transformed celebrity status. Lenny Marlina's immersion in her new role as a fulltime housewife to an important politician is supported by images where she poses with different former presidents. I argue that this kind of manouvre can be thought of as a form of "postfeminist representational culture" the ways in which Lenny Marlina manifests the feminist aspiration but at the same time embodies the 
typical "postfeminist sensibilities" (Genz 2006; Gill \& Herdieckerhoff 2006; McRobbie 2004).

Although the auto/biographical voice of Lenny Marlina presents herself as an ordinary wife, and not as a celebrity in her own right, her everyday life is still extraordinary. Many of the seemingly everyday images of her with her husband actually reflect her extensive travel. These foreign settings highlight her extraordinariness and distinctiveness. They also emphasize her high social status. Again, her everyday images, while partially representing her as ordinary, secure her extraordinariness and sustained celebrity status. In fact, there are twenty three travel photographs included in her auto/biography, twenty of which were taken abroad with her second husband. These images construct Lenny Marlina as a teenaged-girl, having a good time with her boyfriend. Age is not negotiated through the display of youthful body image, rather through a "girling" process of older women, which according to Jermyn (2012, p.1) "is symptomatic of postfeminist culture and indicative of a move to push back the boundaries of ageing". Therefore, I argue that her travel photographs present a complex image of the new mode of femininity that she has embraced through the marriage.

It is this particular portrayal of ageing femininity that distinguishes Lenny Marlina's celebrity femininity from that of Titiek Puspa. Lenny Marlina's present is largely represented by images of her with her second husband and the new family she enters through this marriage. Through these images, I argue that her second husband is signified as the central marker of her new femininity, supposedly different from her previous celebrity femininity. Although she continues to present herself as a fashionable subject, she aims for a more domestic and everyday version of femininity. She embraces her age to the extent that she is even portrayed in trainers in what could otherwise be unappealing poses. I argue that these poses draw on ideals of the contented wife and move away from the glamorous celebrity. As a wife of a politician, she projects a more restrained and conservative image. Thus, her glamour is shown through objects such as the luxurious home that she establishes and the expensive painting that represents her Chinese astrology sign, i.e. the horse rather than through her own appearance.

The images of a good mother and wife are also closely tied to the portrayal of her as a good Muslim. This can be particularly seen in the chapter "Umrah and Hajj Pilgrimage". In this chapter Lenny Marlina talks about her spiritual journey in conjunction with the happiness that she gains from her second marriage. She marks the third pilgrimage that she made with her second husband as the restoration of her position as a wife that can financially count on her husband as she remarks (Said et al. 2004, p.128):

What also felt different was that Mas Bambang paid for this pilgrimage. I had to pay for the two previous pilgrimages.' Thus this time I experienced a really beautiful pilgrimage that was full of spiritual meanings that I did not get in my previous pilgrimages.... I also felt the pleasure of cooking for my husband, even though we were in a special pilgrimage group ${ }^{2}$

The pilgrimage is depicted as another crucial marker of her new femininity, one in which she can submit more completely to her husband. This is particularly due to the fact that in the second marriage she can financially depend on her husband, contrary to her first marriage when she had to support her family including her husband's hobbies and business. As the narrative goes, the feeling of being able to submit completely to her husband enhances her sense

1 She took the first pilgrimage with her mother in 1991, against her first husband's will and the second with her husband in1996, which she said "ended up in our divorce"(Said et al., 2004: 127-128) .

2 The special pilgrimage group refers to what in Bahasa Indonesia is known as ONH Plus. In Indonesia pilgrimage is arranged by the government. The people who want to go on a pilgrimage have to pay ONH (Cost of making the pilgrimage to Mecca). $\mathrm{ONH}$ plus is arranged by private companies and it offers luxury that is not given if one is on the government's scheme. 
of spirituality. The many images scattered throughout the auto/biography further emphasize her religiosity. In these images she is portrayed performing different rituals in Islam, including the Hajj and the recitation of Al Qur'an. She is also pictured as a good humanitarian through the charity work that she does for orphans, a deed that is considered an obligation in Islam. Thus, through the different images, Lenny Marlina performs her femininity as a good Muslim and a good wife and mother. In other words, in the context of Indonesian femininity, she enacts a certain kind of Indonesian Muslim femininity. There is particular demand for this role in her new position as a politician's wife. In fact, within Indonesian context, the roles of women as the wives of leaders require women to possess some leadership quality as well, in addition to the ability and capacity to perform the assigned duties as a wife and a mother. Wives of leaders are bound to be leaders of other women, as for instance exemplified by the wives of Islamic religious leaders in pesantrens (Chusniyah \& Alimi, 2015).

As I have shown in this section, in the auto/biography of Lenny Marlina, age is present and celebrated as ageing physicality is embraced in the knowing recognition of its changes. The more candid pictures of the present show how Lenny Marlina the auto/ biographical subject as an ordinary (good, loyal) wife and loving and understanding mother is celebrated. In fact, the transformations of ageing celebrity in both auto/ biographies are linked to the roles as mothers and grandmothers, mostly represented by the inclusion of family pictures. In this case family pictures are instrumental in establishing the image of a happy family. Both Lenny Marlina's and Titiek Puspa's auto/ biographies include a significant number of family pictures, which I argue following Stanley (1992) largely fall into the category of the "high street norm" of family pictures.

As argued by Stanley (1992, p.29), high street photograph conventions produce false representations of women/people that "act as a standard that everyone thinks is or should be attractive and desirable and which they should aspire to or at least give the appearance (sometimes literally) of doing so." Following Stanley (1992), it can be argued that the basic idea of family pictures in general is that people should look happy, relationally connected and appealing. The element of happiness is often highlighted by the building of "harmony", which is observable through the kind of clothing uniforms worn in family pictures. This "uniform" suggests togetherness and familial bonding. Considering the fabrication involved in this process, it is arguable that this kind of photograph somehow presents what Stanley calls a "patterned lie" (1992, p.32). Looking happy or even happiness itself is just an occasion. In the case of family pictures it is an event when certain happiness is created (Sontag, 1979). Family pictures thus secure ideals of the happy family, important in this context because proper Indonesian femininities are closely related to women's roles in the family. Women are located as the pillars of the family. The family pictures of the celebrities included in these auto/biographies reflect the ways in which the private and the public roles of the female celebrity are moulded into a new form where the private and the public are simultaneously lived.

In the cases of both Titiek Puspa's and Lenny Marlina's autobiographies, roles as mother and grandmother are secured by the family pictures of both celebrities. This particular role of being a grandmother is linked to notions of ageing for these auto/biographical subjects, unique in these book-length auto/biographies. These family pictures allow these two auto/biographical subjects to extend their femininity beyond motherhood to grandmotherhood, and also to show that despite their age, they are still fit, fashionable, functional and flexible, both within the personal as well as public domains.

\section{CONCLUSION}

In this paper on ageing femininity I have discussed how photographic narratives in the auto/biographies of ageing celebrities can be used as a site where the age of the auto/ 
biographical subject is re-negotiated. This is particularly important because of conventional norms of popular culture regarding beauty and youthfulness. I argue as well that such portrayal of youthful ageing celebrities may affect the construction of beauty that will further pressure women of all ages to meet the demand of normative beauty. As a note, among others, the mushrooming of beauty centers can be regarded as the widely spread beauty ideology that has become the everyday practice of millions of women (Murlianti, 2014). In this article, I have shown how ageing celebrities transform and extend their forms of femininity as they age. Particularly in the case of Lenny Marlina's auto/biography, Lenny Marlina the auto/ biographical subject is portrayed as transforming her glamorous femininity to a more conventional form of femininity whose primary roles are as a wife and a mother, while in Titiek Puspa's auto/biography, the auto/ biographical subject is continuously portrayed as a glamorous celebrity despite her age. In the case of both auto/biographies discussed in this section, the auto/biographical subjects extend their performance of femininity to grandmotherhood as shown in both family pictures. Having examined the various forms of the representation of femininities, I also argue that the ageing auto/biographical subjects continue to occupy both the private and public spheres and the two spheres are blurred and intermingling in the production of these auto/ biographical subjects, constantly showing their attributes of the Third Agers: being fit, fashionable, functional and flexible.

\section{ACKNOWLEDGEMENT}

The original version of this paper was commissioned by the Asian Association of Women's Studies (AAWS) as part of the Korea-ASEAN Collaborative Research Project supported by the ASEAN-ROK Cooperation Fund.

\section{REFERENCES}

Bakhtin, M. M. 1981. The Dialogic Imagination: Four
Essays by M.M. Bakhtin (C. Emerson \& M. Holquist, Trans.). In M. Holquist (Ed.). Austin: University of Texas Press.

Barbara, L. M., \& Momin, R. 2015. Celebrity, Ageing and the Construction of Third Age Identities. International Journal of Cultural Studies, 18(6), pp.577-593.

Biggs, S. 2004. Age, Gender, Narratives, and Masquerades. Journal of Aging Studies, 18, pp.45-48.

Bildtgård, T. 200o. The Sexuality of Elderly People on FilmVisual Limitations. Journal of Aging and Identity Journal of Aging and Identity, 5(3), pp. 169-183.

Chusniyah, S., \& Alimi, M. Y. 2015. Nyai Dadah : The Elasticity of Gender Roles and Life History of Pesantren Woman Leader. Jurnal komunitas, 7(1).

Cosslett, T., Lury, C., \& Summerfield, P. (Eds.). 2000. Feminism and Autobiography: Text, Theories, Methods. London, New York Routledge.

Dugdale, T. 1999. 'Telling it like it was?!': A Critical Interpretive Analysis of Discursive Strategies in Contemporary Star (Auto)Biographies. (PhD), Wayne State University, Detroit, Michigan.

Dyer, R. 1987. Heavenly Bodies: Film Stars and Society. Great Britain: Macmillan Press.

Eakin, P. J. (Ed.) 1989. On Autobiography. Minneapolis, London: University of Minnesota Press.

Endah, A. 2008. Titiek Puspa: A Legendary Diva. Jakarta: PT Gramedia Pustaka Utama.

Entwistle, J. 200o. The Fashioned Body : Fashion, Dress, and Modern Social Theory. Cambridge; Malden, MA: Polity Press ; Blackwell.

Gamson, J. 1994. Claims to Fame: Celebrity in Contemporary America. Berkeley: University of California.

Genz, S. 2006. Third Waylve. Feminist Theory, 7(3), pp. 333-353.

Gill, R., \& Herdieckerhoff, E. 20o6. Rewriting the Romance: New Femininities in Chicklit. Feminist Media Studies, 6(4).

Ingraham, C. 2008. White weddings : romancing heterosexuality in popular culture. New York [u.a.]: Routledge.

Jermyn, D. 2012. Get a life, ladies. Your old one is not coming back: Ageing, Ageism and the Lifespan of Female Celebrity. Celebrity Studies, 3(1), pp. 1-12.

Jerslev, A. 2017. The elderly female face in beauty and fashion ads: Joan Didion for CÈline. European Journal of Cultural Studies European Journal of Cultural Studies, 136754941770843.

Lejeunne, P. 1989. The Autobiographical Pact (K. Leary, Trans.). In P. J. Eakin (Ed.), On Autobiography. Minneapolis \& London: University of Minnesota Press.

Lesmana, F. 2013. 10 Artis Indonesia Yang Diduga Pernah Operasi Plastik (10 Indonesian Actresses Suspected to have had Plastic Surgery). Wow Menariknya. Retrieved from http://www.wowmenariknya.com/2013/12/10-artis-indonesiayang-diduga-pernah.html 
Littler, J. 2004. Making Fame Ordinary: Intimacy, Reflexivity and 'Keeping It Real'. Mediactive(2), pp. 8-25.

Marcus, L. 1994. Auto/Biographical Discourses: Theory, Criticism, Practice. Manchester and New York: Manchester University Press.

Marshall, B. L. 2017. Happily ever after? Successful ageing and the heterosexual imaginary. European Journal of Cultural Studies European Journal of Cultural Studies(4), 136754941770843.

Marshall, D. P. 2001. Celebrity and Power - Fame in Contemporary Culture. Minneapolis, London: University of Minnesota Press.

McRobbie, A. 2004. Post-Feminism and Popular Culture. Feminist Media Studies, 4(3), pp. 255-264.

Murlianti, S. 2014. Cycles of Beauty Culture: Ethnography of Beauty Clinics Commodification. jurnal komunitas, 6(2), pp. 327-335.

Said, T., Said, S., Said, L., Alhasany, M., Titien Sukmono, \& Yuni. 2004. Si Lenny dari Ciateul, Otobiografi Lenny Marlina (Si Lenny from Ciateul, Autobiography of Lenny Marlina).

Sontag, S. 1979. In Plato's Cave On Photography. London: Penguin Books.

Stanley, L. 1992. The Auto/Biographical I : Theory and
Practice of Feminist Autobiography: Manchester University Press.

Stanley, L., \& Wise, S. 2002. Breaking Out Again: Feminist Ontology and Epistemology. London and New York: Routledge.

Turner, G. 2004. Understanding celebrity: Sage.

Twigg, J. 2017. Fashion, the media and age: How womens magazines use fashion to negotiate age identities. European Journal of Cultural Studies European Journal of Cultural Studies, 136754941770843.

Ussher, J. M. 1997. Fantasies of Femininity: Reframing the Boundaries of Sex. London: Penguin Books.

Vares, T. 2009. Reading the 'Sexy Oldie': Gender, Age(ing) and Embodiment. Sexualities, 12(4), pp.503-524. 